\title{
The P3 O-Tert-Butyl-Threonine is Key to High Cellular and Antiviral Potency for Aldehyde-Based SARS-CoV-2 Main Protease Inhibitors
}

Yuying Ma ${ }^{\mathrm{a}, \dagger}$, Kai S. Yang ${ }^{\mathrm{a}, \dagger}$, Zhi Zachary Geng ${ }^{\mathrm{a}, \dagger}$, Yugendar R. Alugubellia, ${ }^{\mathrm{a}}$, Namir Shaabani, ${ }^{\mathrm{b}, \dagger}$ Erol C. Vatansever $^{a, \dagger}$, Xinyu R. Ma ${ }^{a, \dagger}$, Chia-Chuan Cho ${ }^{a, \dagger}$, Kaustav Khatua ${ }^{a, \dagger}$, Lauren Blankenship ${ }^{a}$, Ge Yu ${ }^{a}$, Banumathi Sankaran $^{\mathrm{c}}$, Pingwei $\mathrm{Li}^{\mathrm{d}}$, Robert Allen ${ }^{\mathrm{b}}$, Henry Ji ${ }^{\mathrm{b},{ }^{*}}$, Shiqing $\mathrm{Xu}^{\mathrm{a},{ }^{*},}$, and Wenshe Ray Liu ${ }^{\mathrm{a}, \mathrm{d}, \mathrm{ef},{ }^{*}}$

${ }^{a}$ Texas A\&M Drug Discovery Laboratory, Department of Chemistry, Texas A\&M University, College Station, TX 77843, USA

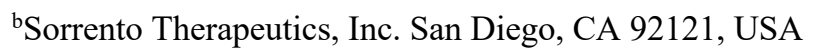

${ }^{\mathrm{c}}$ Molecular Biophysics and Integrated Bioimaging, Berkeley Center for Structural Biology, Laurence Berkeley National Laboratory, Berkeley, CA 94720, USA

${ }^{\mathrm{d} D e p a r t m e n t ~ o f ~ B i o c h e m i s t r y ~ a n d ~ B i o p h y s i c s, ~ T e x a s ~ A \& M ~ U n i v e r s i t y, ~ C o l l e g e ~ S t a t i o n, ~ T X ~ 77843, ~ U S A ~}$

${ }^{\mathrm{e}}$ Institute of Biosciences and Technology and Department of Translational Medical Sciences, College of Medicine, Texas A\&M University, Houston, TX 77030, USA

fDepartment of Molecular and Cellular Medicine, College of Medicine, Texas A\&M University, College Station, TX 77843, USA

${ }^{\dagger}$ Contributed equally to the paper.

*Correspondence should be addressed to Henry Ji: hii@sorrentotherapeutics.com, Shiqing Xu: shiqing.xu@tamu.edu and Wenshe Ray Liu: wsliu2007@tamu.edu

Supporting Information Placeholder

ABSTRACT: As an essential enzyme to SARS-CoV-2, main protease $\left(\mathrm{M}^{\mathrm{Pro}}\right)$ is a viable target to develop antivirals for the treatment of COVID-19. By varying chemical compositions at both $\mathrm{P} 2$ and $\mathrm{P} 3$ sites and the $N$-terminal protection group, we synthesized a series of $\mathrm{M}^{\text {Pro }}$ inhibitors that contain $\beta$-(S-2-oxopyrrolidin-3-yl)-alaninal at the P1 site. These inhibitors have a large variation of determined $\mathrm{IC}_{50}$ values that range from 4.8 to $650 \mathrm{nM}$. The determined $\mathrm{IC}_{50}$ values reveal that relatively small side chains at both $\mathrm{P} 2$ and $\mathrm{P} 3$ sites are favorable for achieving high in vitro $\mathrm{M}^{\text {Pro }}$ inhibition potency, the $\mathrm{P} 3$ site is tolerable toward unnatural amino acids with two alkyl substituents on the $\alpha$-carbon, and the inhibition potency is sensitive toward the $N$-terminal protection group. X-ray crystal structures of $\mathrm{M}^{\text {Pro }}$ bound with 16 inhibitors were determined. All structures show similar binding patterns of inhibitors at the $\mathrm{M}^{\text {Pro }}$ active site. A covalent interaction between the active site cysteine and a bound inhibitor was observed in all structures. In $\mathrm{M}^{\text {Pro }}$, large structural variations were observed on residues N142 and Q189. All inhibitors were also characterized on their inhibition of $\mathrm{M}^{\text {Pro }}$ in $293 \mathrm{~T}$ cells, which revealed their in cellulo potency that is drastically different from their in vitro enzyme inhibition potency. Inhibitors that showed high in cellulo potency all contain $O$-tert-butyl-threonine at the P3 site.
Based on the current and a previous study, we conclude that $O$-tert-butyl-threonine at the $\mathrm{P} 3$ site is a key component to achieve high cellular and antiviral potency for peptidyl aldehyde inhibitors of $\mathrm{M}^{\mathrm{Pro}}$. This finding will be critical to the development of novel antivirals to address the current global emergency of concerning the COVID19 pandemic.

\section{- INTRODUCTION}

COVID-19 is the prevailing pandemic that has ravaged much of the world. As the COVID-19 pathogen, SARS$\mathrm{CoV}-2$ uses its membrane Spike protein to recognize the human receptor ACE2 for infection. ${ }^{1-2}$ Current COVID19 vaccines all target this process for the neutralization of the virus. However, the continuous emergence of new viral strains that evade vaccines demands other antivirals to be developed as well. SARS-CoV-2 has a very large open reading frame ORF1ab that is translated to two large polypeptides pp1a and pp1b in the human cell host. ${ }^{3-4}$ The processing of ppla and pplb to 16 nonstructural proteins (nsps) that are functionally critical to the viral replication relies on proteolytic activities of two internal nsp fragments, nsp3 and nsp5. ${ }^{5}$ Nsp5 is also called 3C-like 
protease and more recently main protease $\left(\mathrm{M}^{\mathrm{Pro}}\right)$. Since $\mathrm{M}^{\mathrm{Pro}}$ hydrolyzes 13 out of the total of 16 nsps, it has been considered as a viable target for the development of antivirals. In the past year, a number of papers have been published on the development of peptidyl aldehydes that contain $\beta$-(S-2-oxopyrrolidin3 -yl)-alaninal (opal) at the $\mathrm{P} 1$ position as potent $\mathrm{M}^{\text {Pro }}$ inhibitors. ${ }^{6-14}$ Other inhibitors were developed as well. ${ }^{15-28}$ However, systematic structure-activity relationship (SAR) studies of opal-based $\mathrm{M}^{\mathrm{Pro}}$ inhibitors are needed. In the current study, we explore variations at the P2 and $\mathrm{P} 3$ sites and the $N$-terminal protection group in opal-based peptidyl $\mathrm{M}^{\text {Pro }}$ inhibitors. These inhibitors were characterized in their in vitro and in cellulo inhibition of $\mathrm{M}^{\text {Pro }}$ and their interactions with $\mathrm{M}^{\text {Pro }}$ by $\mathrm{X}$-ray protein crystallography. Our study reveals that $O$-tert-butyl-threonine at the P3 site in an opalbased $\mathrm{M}^{\text {Pro }}$ inhibitor is critical to achieve high cellular and antiviral potency.

\section{— RESULTS}

The Design and Synthesis of MPI11-

28. In previous studies, we developed MPI1-10 and characterized both their $\mathrm{M}^{\mathrm{Pro}}$ inhibition potency and their antiviral potency. ${ }^{13-14}$ As a tripeptidyl aldehyde, MPI8 shows the highest antiviral potency with an $\mathrm{EC}_{50}$ value of $30 \mathrm{nM}$ to neutralize SARSCoV-2 (USA-WA1/2020) in Vero E6 cells. ${ }^{29}$ MPI3, another tripeptidyl aldehyde doesn't have high antiviral potency. However, it has the highest in vitro $\mathrm{M}^{\text {Pro }}$ inhibition potency with an $\mathrm{IC}_{50}$ value as $8.5 \mathrm{nM} .^{13}$ To explore how substituents at different positions in a tripeptidyl opalbased $\mathrm{M}^{\text {Pro }}$ inhibitor (shown on the top of Figure 1) influence its potency, we decided to carry out a systematic SAR study. We maintained opal at the P1 position due to its established preferential binding to the $\mathrm{M}^{\mathrm{Pro}} \mathrm{P} 1$ binding pocket and its covalent adduct formation with $\mathrm{C} 145$, the $\mathrm{M}^{\text {Pro }}$ catalytic cysteine. $\mathrm{M}^{\text {Pro }}$ tolerates leucine and phenylalanine at the P2 site of a substrate. Therefore, we chose to vary this site in our inhibitor design with $\beta$-alkyl alanines with a size between or around leucine and phenylalanine. Chosen alkyl substituents are isopropyl, phenyl, cyclohexyl, t-butyl, isopropenyl, cycopropyl, 2-furyl, and 2thienyl. $\mathrm{M}^{\text {Pro }}$ doesn't have a binding
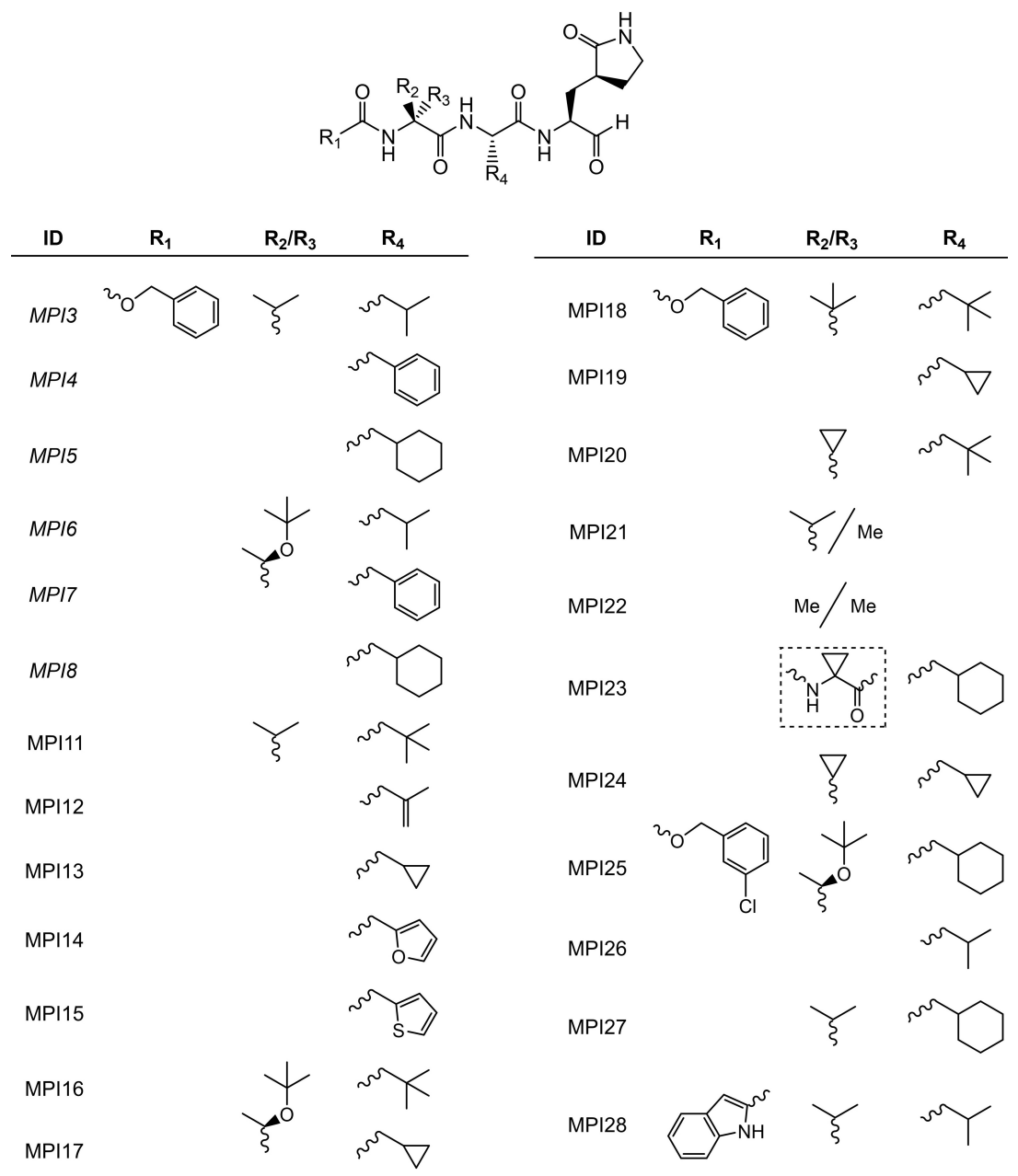

Figure 1. Structures of tripeptidyl $\mathrm{M}^{\text {Pro }}$ inhibitors MPI11-28. Inhibitors that have just a single component at $\mathrm{R}_{2} / \mathrm{R}_{3}$ shown contain a hydrogen at the $\mathrm{R}_{3}$ position. MPI3-8 were previously developed and are shown for comparison.

pocket for the $\mathrm{P} 3$ residue in a substrate. However, native $\mathrm{M}^{\text {Pro }}$ substrates have valine or a similar size residue at this position. Based on known opal inhibitors and substrates of $\mathrm{M}^{\text {Pro }}$, we varied this site with amino acids including valine, $O$-tert-butyl-threonine, $L$-cyclopropylglycine, $L$ tert-butyl-glycine, $L$ - $\alpha$-methyl-valine, dimethylglycine, and 1-aminocyclopropane-1-carboxylate. The $N$-terminal protection group was chosen between CBZ, $m$-chloro $\mathrm{CBZ}$, and indole-2-carboxylate due to their demonstrated

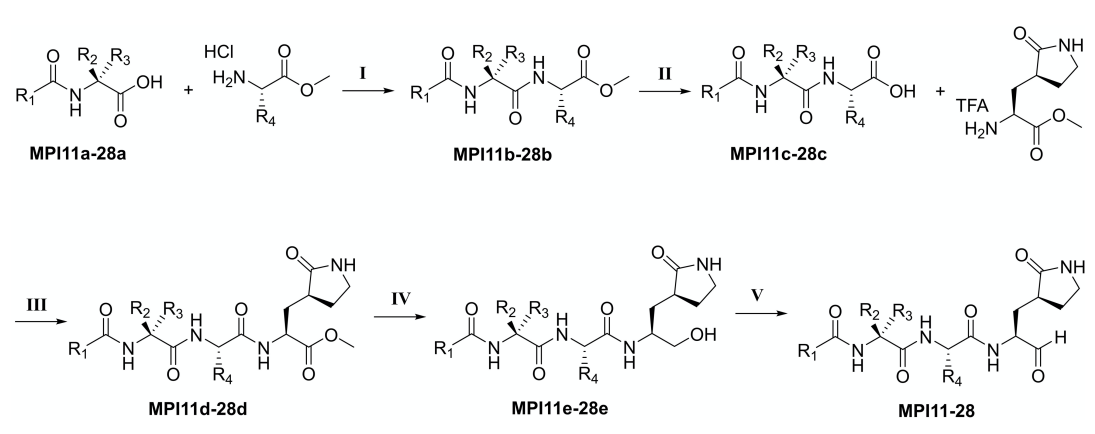

Scheme 1. Reagents and conditions: (I) HATU, DIPEA, DMF; (II) $\mathrm{LiOH} \cdot \mathrm{H}_{2} \mathrm{O}$, THF/H $\mathrm{H}_{2} \mathrm{O}$; (III) HATU, DIPEA, DMP; (IV) $\mathrm{LiBH}_{4}$, THF; (V) DMP, DCM. 
contributions to antiviral potency. ${ }^{6,10}$ A total of 18 new $\mathrm{M}^{\text {Pro }}$ inhibitors, designated as MPI11-28 shown in Figure 1 , were designed. We synthesized all inhibitors according to the synthetic route shown in Scheme 1. In this synthesis, a P2 amino acid ester was conjugated with a $N$-protected $\mathrm{P} 3$ amino acid and the afforded product was then hydrolyzed to free its $C$-terminal carboxylate for reaction with $\beta$-(S-2-oxopyrrolidin-3-yl)-alanine ester. An obtained tripeptidyl ester was reduced to afford a $C$-terminal alcohol that was then oxidized via Dess-Martin oxidation in a mild condition to make a final product.
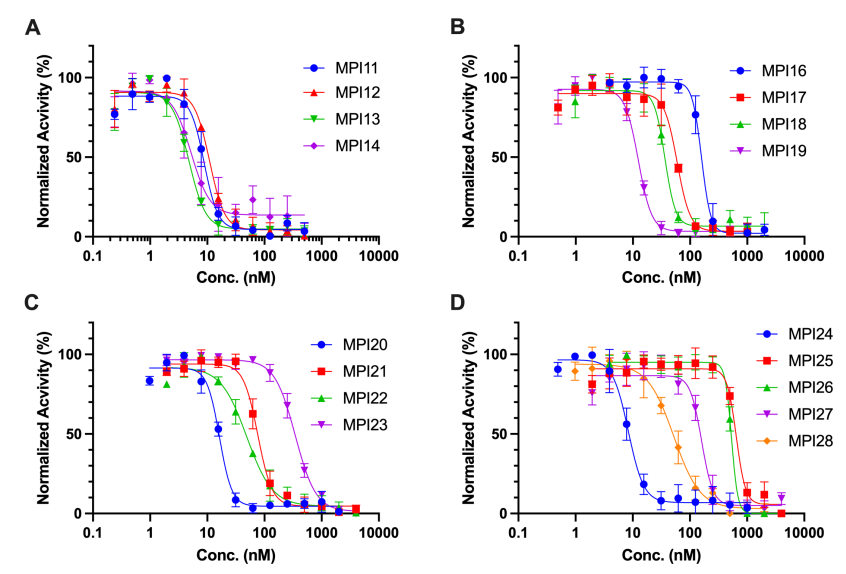

Figure 2. Inhibition curves of MPI11-28 on $\mathrm{M}^{\text {Pro }}$. Triplicate experiments were performed for each compound. For all experiments, 20 or $10 \mathrm{nM} \mathrm{M}^{\text {Pro }}$ was incubated with an inhibitor for $30 \mathrm{~min}$ before $10 \mu \mathrm{M}$ Sub3 was added. The $\mathrm{M}^{\text {Pro }}$-catalyzed Sub3 hydrolysis rate was determined by measuring linear increase of product fluorescence (Ex: $336 \mathrm{~nm} / \mathrm{Em}: 455 \mathrm{~nm}$ ) for 5 min.

Kinetic characterizations of MPI11-28 on their enzymatic inhibition of $\mathbf{M}^{\text {Pro }}$. We followed a previously established protocol that uses Sub3, a fluorogenic peptide substrate of $\mathrm{M}^{\mathrm{Pro}}$ to determine $\mathrm{IC}_{50}$ values for MPI11-28. ${ }^{28} \mathrm{In}$ this assay, we preincubated $\mathrm{M}^{\text {Pro }}$ with an inhibitor for 30 min before Sub3 was added and the fluorescent product formation was recorded in a fluorescence plate reader. Except MPI15 that is insoluble in DMSO and therefore was not characterized, all other inhibitors displayed well traceable inhibition curves as shown in Figure 2. We fit all data to a four-parameter variable slope inhibition equation in GraphPad 9.0 to obtain $\mathrm{IC}_{50}$ values for all inhibitors. As shown in Table 1, MPI11-28 display a large variation of $\mathrm{IC}_{50}$ values that ranges from 4.8 to $650 \mathrm{nM}$. MPI11-14 all contain valine at the P3 site. They have the lowest $\mathrm{IC}_{50}$ values among all newly developed $\mathrm{M}^{\text {Pro }}$ inhibitors. MPI13-14 have determined $\mathrm{IC}_{50}$ values around 5 $\mathrm{nM}$. Since $10 \mathrm{nM} \mathrm{M}^{\text {Pro }}$ is the lowest enzyme concentration we can use to do the inhibition analysis, $5 \mathrm{nM}$ is technically the lowest $\mathrm{IC}_{50}$ value we can detect. Therefore, $\mathrm{M}^{\text {Pro }}$ inhibition potency for MPI13-14 is likely higher than what the numbers shown in Table 1 indicate. In comparison to MPI13-14, MPI11-12 have slightly higher IC C $_{50}$ values that are around $10 \mathrm{nM}$. In previous work, we developed another three $\mathrm{M}^{\mathrm{Pro}}$ inhibitors MPI3-5 that also contain a valine at the $\mathrm{P} 3$ site. All three have low $\mathrm{IC}_{50}$ values.
All 7 inhibitors that have valine at the $\mathrm{P} 3$ site and a $N$ terminal CBZ protection group are among the most potent $\mathrm{M}^{\text {Pro }}$ inhibitors in vitro. A P3 valine apparently favors the enzyme inhibition kinetics. A comparison of all seven inhibitors also reveals that a residue at the $\mathrm{P} 2$ site with a size close to leucine leads to better $\mathrm{M}^{\text {Pro }}$ inhibition. $\beta-\mathrm{Cy}-$ clopropyl alanine and $\beta$-(furan-2yl) alanine that have a more rigid side chain than leucine favor the enzyme inhibition kinetics more. MPI6-8 that have a P3 O-tert-butylthreonine were developed previously and showed high cellular and antiviral potency. We synthesized two more $\mathrm{M}^{\text {Pro }}$ inhibitors with a P3 O-tert-butyl-threonine, MPI1617. Both have an $\mathrm{IC}_{50}$ value similar to MPI6-8. Varying the $\mathrm{P} 2$ position does not seem to significantly change in vitro $\mathrm{M}^{\text {Pro }}$ inhibition potency among this group of inhibitors. To explore further on whether variations at the P3 site lead to different inhibition potency, we developed MPI18-24. Variants include two dialkyl glycines and 1aminocyclopropane-1-carboxylate that are not standard $L$-amino acids. Except MPI23 that contains a P3 1-aminocyclopropane-1-carboxylate, all other inhibitors have an $\mathrm{IC}_{50}$ value below $100 \mathrm{nM}$. The more rigid P3 residue in MPI23 likely contributes to its less favorable $\mathrm{M}^{\text {Pro }}$ inhibition kinetics. MPI24 is structurally similar to MPI13. Its enzyme inhibition potency is similar to MPI13 as well. Three inhibitors MPI25-27 that have a $\mathrm{N}$-terminal $\mathrm{m}$ chloro CBZ group were developed and characterized as well. In comparison to their regular CBZ-containing counterpart inhibitors MPI8, MPI6, and MPI5, they display more than 5-fold higher $\mathrm{IC}_{50}$ values. Apparently adding a $m$-chloro substituent to the terminal CBZ group doesn't improve in vitro enzyme inhibition potency. MPI28 has a $N$-terminal indole-2-carboxylate. In comparison to its CBZ counterpart inhibitor MPI3, MPI28 has a 6-folder higher $\mathrm{IC}_{50}$ value. In comparison to indole-2-carboxylate, it is evident that CBZ serves as a better $N$-terminal group for improved in vitro enzyme inhibition potency.

X-Ray Crystallography analysis of $\mathrm{M}^{\text {Pro }}$ bound with 16 different inhibitors. To characterize our developed inhibitors in their interactions with $\mathrm{M}^{\mathrm{Pro}}$, we crystallized $\mathrm{M}^{\text {Pro }}$ in its apo form, soaked apo- $\mathrm{M}^{\text {Pro }}$ crystals with different inhibitors and then determined structures of $\mathrm{M}^{\text {Pro }}$ bound with different inhibitors using X-ray crystallography. Among 17 inhibitors that we used to soak crystals, 16 were observable in the active site of $\mathrm{M}^{\text {Pro }}$. All structures were determined in high resolutions (Table S1). $2 \mathrm{~F}_{0}-\mathrm{F}_{\mathrm{c}}$ electron density map around each inhibitor clearly shows a covalent interaction with $\mathrm{C} 145$ of $\mathrm{M}^{\text {Pro }}$ to generate a hemithioacetal (Figure 3A). In all formed hemithioacetals, the hemithioacetal alcohol takes an $S$ configuration. In most structures, electron density around inhibitors is well shaped for modeling the $\mathrm{P} 1$ opal, $\mathrm{P} 2$, and $\mathrm{P} 3$ residues. For MPI12, the isopropenyl group shows weak electron density around its 1- and 3-carbon atoms indicating that the group is probably freely rotating around its 2-carbon atom in the active site of $\mathrm{M}^{\text {Pro }}$. Although a few $\mathrm{M}^{\text {Pro }}$-inhibitor 
A

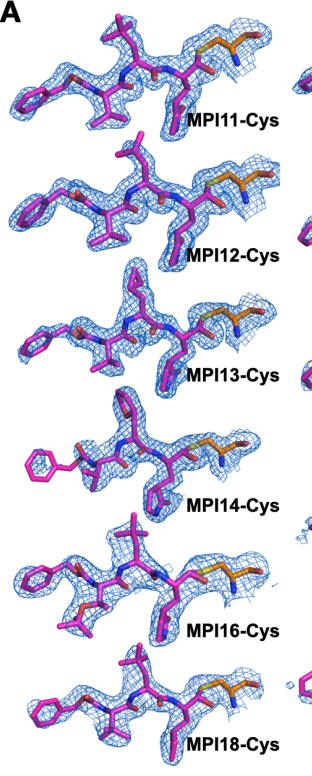

D

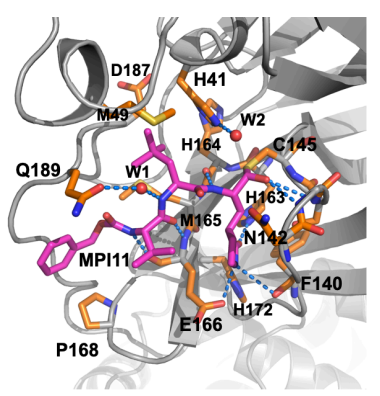

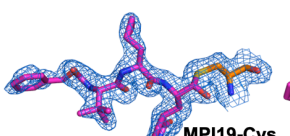
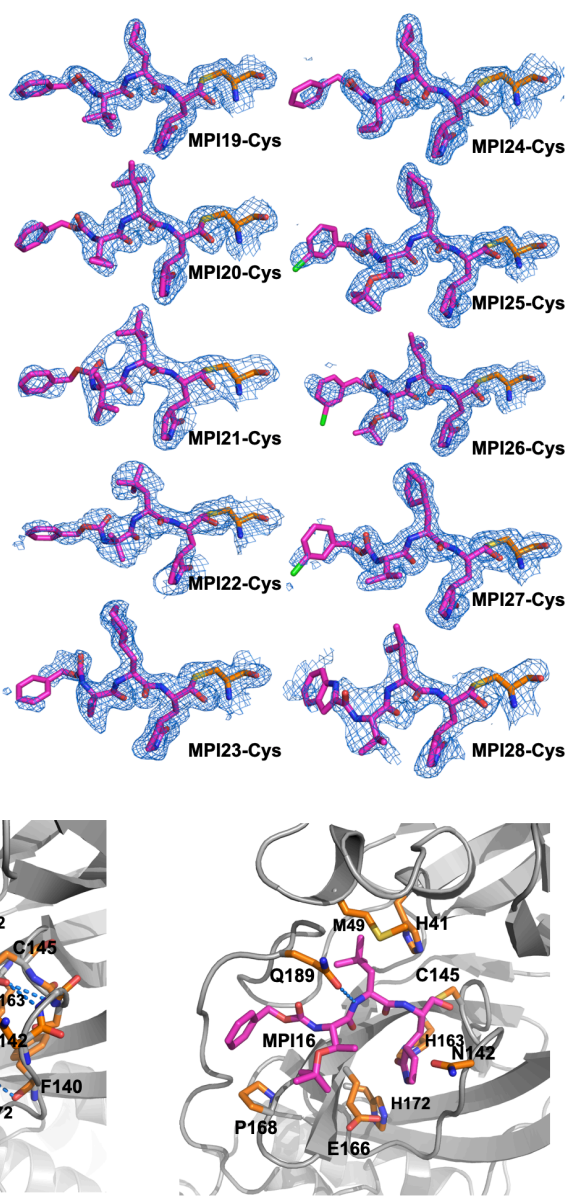

B
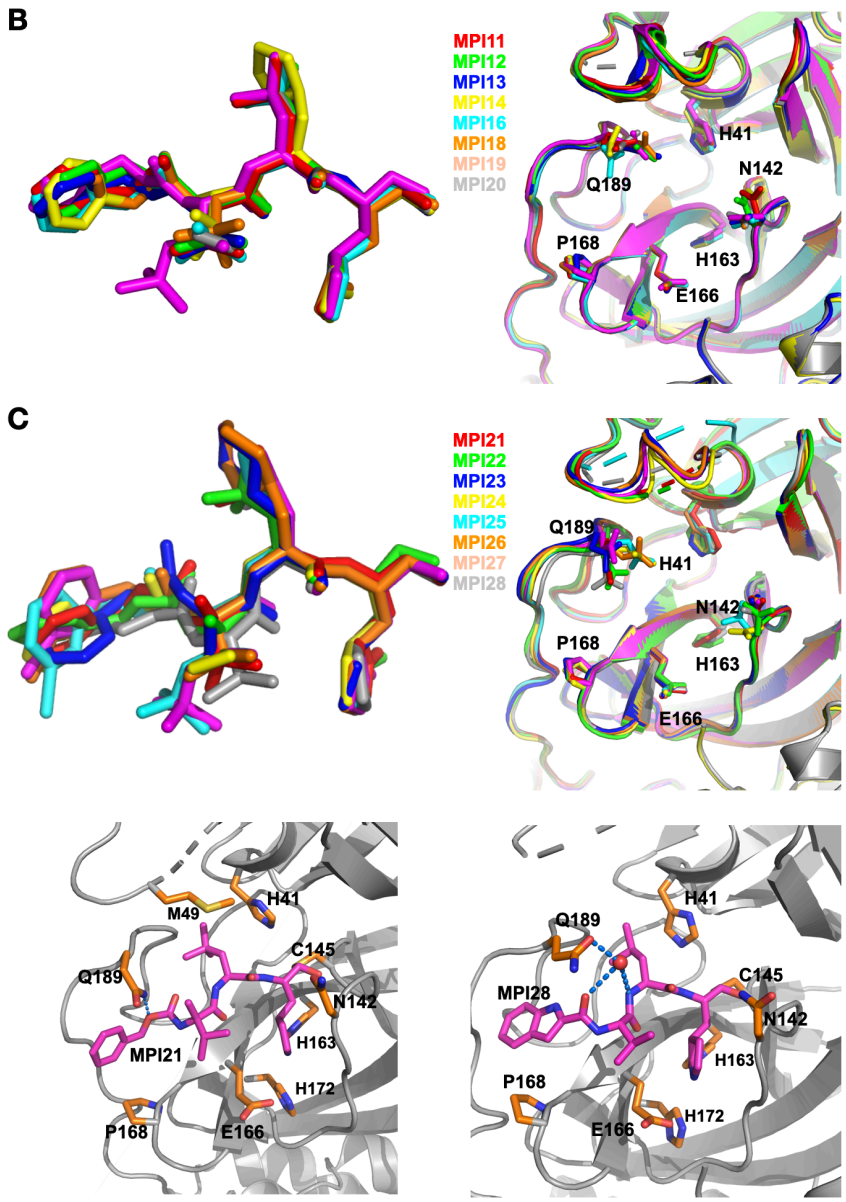

Figure 3. Crystal structures of $\mathrm{M}^{\text {Pro }}$ bound with $16 \mathrm{MPIs}$. (A) Contoured $2 F_{o}-F_{c}$ maps at the $1 \sigma$ level around $16 \mathrm{MPIs}$ and C145 in the active site of MPro. (B) Superposition of MPro complexes with 8 MPIs including MPI11-14, MPI16, and MPI18-20. Inhibitors on the left and proteins on the right are presented separately for clarity. (C) Superposition of MPro complexes with MPI21-28. Inhibitors and proteins are shown separately. (D) Interactions between the inhibitor and active site residues in MPro complexes with MPI11, MPI16, MPI21, and MPI28. Some of hydrogen bonds between ligands and Mro are shown as blue dotted lines.

complexes have electron density that can be used to model the $N$-terminal group, the majority have relatively weak electron density around the $N$-terminal group indicating weak binding of the $N$-terminal group at the active site. Superpositioning all $\mathrm{M}^{\mathrm{Pro}}$-inhibitor complexes shows a similar binding mode for all inhibitors to the $\mathrm{M}^{\text {Pro }}$ active site (Figures 3B and 3C). MPI28 displays the most difference from other inhibitors due to its unique $N$-terminal indole-2-carboxylate. All other inhibitors show very similar binding to $\mathrm{M}^{\text {Pro }}$ except that different orientations are adopted at the relatively flexible $N$-terminal group. In all $\mathrm{M}^{\mathrm{Pro}}$-inhibitor complexes, the protein shows a similar structure except at two residues N142 and Q189 and the M49-containing helix. Both N142 and Q189 adopt varied orientations in different $\mathrm{M}^{\mathrm{Pro}}$-inhibitor structures and the M49-containing helix is structurally rearranged and not visible in most $\mathrm{M}^{\mathrm{Pro}}$-inhibitor complexes. Due to a large number of crystal structures that are presented in this work, we will focus on only four representative $\mathrm{M}^{\mathrm{Pro}}$-inhibitor complexes to describe structure variations of $\mathrm{M}^{\text {Pro }}$ at the active site. In $\mathrm{M}^{\mathrm{Pro}}$-MPI11 as shown in Figure 3D, MPI11 forms extensive hydrogen bonds with $\mathrm{M}^{\text {Pro }}$. The hemithioacetal hydroxyl group forms two hydrogen bonds with two backbone amide nitrogen atoms explaining its exclusive $S$ configuration. The opal side-chain amide forms three hydrogen bonds with E166, N142, and F140 and its backbone nitrogen forms a hydrogen bond with H164. The side chain of the P2 $\beta$-tert-butyl-alanine (4-methyl-leucine) involves van der Waals interactions with $\mathrm{M}^{\mathrm{Pro}}$ residues surrounding the $\mathrm{P} 2$ binding pocket including M49, H41, M165, D187, and Q189. Its $\alpha$-nitrogen interacts with the side chain of Q189 indirectly through a water molecule. The P3 residue of MPI11 forms two hydrogen bonds with backbone nitrogen and oxygen atoms of E166. The $N$-terminal CBZ of MPI11 interacts hydrophobically with the backbone of the Q189-containing loop and the side chain of P168. In $\mathrm{M}^{\mathrm{Pro}}$-MPI11, the side chain of N142 flips away from the opal side chain of MPI11. MPI16 interacts with $\mathrm{M}^{\text {Pro }}$ similar to MPI11. Notable differences are at N142 and Q189. N142 forms van der Waals interactions with the opal oxopyrrolidine ring and Q189 forms a hydrogen bond directly with the backbone nitrogen of the P2 residue. In $\mathrm{M}^{\mathrm{Pro}}$-MPI21, N142 adopts a conformation away from the opal side chain and Q189 forms a hydrogen bond with a CBZ carbamate oxygen atom. MPI28 has a different $N$-terminal group. 
Interactions involving its $N$-terminal group are different from other inhibitors. The indole-2-carboxyl oxygen forms a hydrogen bond with a water molecule that also forms hydrogen bonds with Q189 and the backbone nitrogen of the $\mathrm{P} 2$ residue.
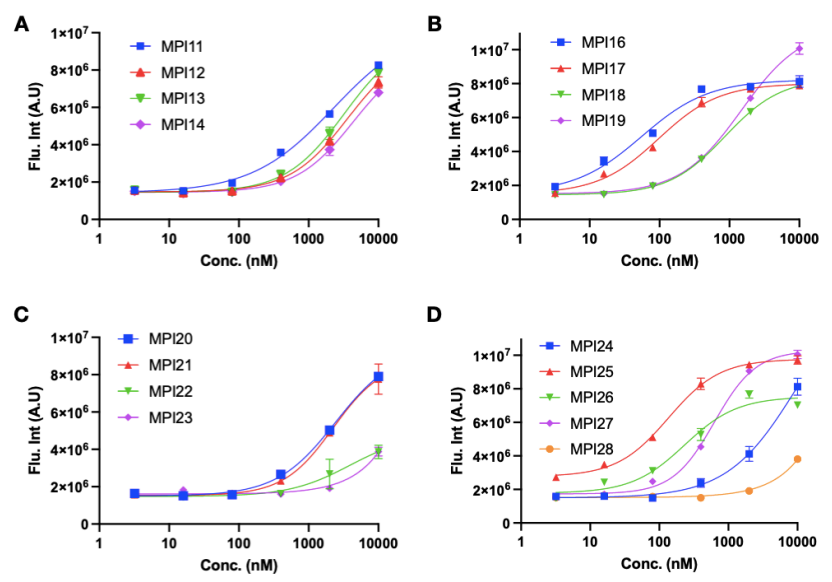

Figure 4. Cellular potency of MPI11-28 in their inhibition of $\mathrm{M}^{\text {Pro }}$ to drive host $293 \mathrm{~T}$ cell survival and overall $\mathrm{M}^{\text {Pro }}$-eGFP expression.

Characterizations of Cellular $\mathrm{M}^{\text {Pro }}$ inhibition potency of MPI11-28. $\mathrm{M}^{\text {Pro }}$ is acutely toxic to a human cell host. Using this unique characteristic, we previously developed a cell-based analysis to characterize cellular $\mathrm{M}^{\text {Pro }}$ inhibition potency for $\mathrm{M}^{\text {Pro }}$ inhibitors. ${ }^{29}$ In this assay, an inhibitor with in cellulo potency suppresses cellular toxicity from the expression of an $\mathrm{M}^{\text {Pro }}$-eGFP fusion protein, which leads to enhanced overall expression of $\mathrm{M}^{\mathrm{Pro}}$-eGFP that can be characterized by flow cytometry. We consider this assay more advantageous over a direct antiviral assay in the characterization of $\mathrm{M}^{\text {Pro }}$ inhibitors since a compound may inhibit host proteases such as TMPRSS2, furin, and cathepsin $\mathrm{L}$ that are critical for SARS-CoV-2 infection to provide false positive in cellulo potency results of $\mathrm{M}^{\mathrm{Pro}}$ inhibition. In cellulo potency determined by this method for MPI5-8 agreed well with their antiviral potency that were characterized using SARS-CoV-2 (USA-WA1/2020) in Vero E6 cells. We adopted this assay to characterize MPI11-28 as well. All inhibitors were tested up to $10 \mu \mathrm{M}$ in their inhibition of $\mathrm{M}^{\mathrm{Pro}}$-eGFP in human 293T cells. Overall cellular eGFP fluorescence were plotted against the inhibition concentration to obtain their $\mathrm{EC}_{50}$ values. Results are presented in Figure 4 and Table 1. As shown in Figure 4A, MPI11-14 exhibit minimal in cellulo potency to inhibit $\mathrm{M}^{\text {Pro }}$, which is in significant contrast to their very high in vitro enzyme inhibition potency. Since their inhibition curves do not reach a plateau, their $\mathrm{EC}_{50}$ values are estimated as higher than $2 \mu \mathrm{M}$. MPI16-17 are the two most potent inhibitors among MPI11-28 on in cellulo potency with determined $\mathrm{EC}_{50}$ values as $56 \mathrm{nM}$ and $97 \mathrm{nM}$, respectively (Figure 4B). In comparison to MPI16-17, MPI18-19 have weaker in cellulo potency with determined $\mathrm{EC}_{50}$ values as $860 \mathrm{nM}$ and 1,500 $\mathrm{nM}$, respectively. MPI20-23 all have weak in cellulo potency (Figure 4C). MPI22-23 show very low inhibition of $\mathrm{M}^{\text {Pro }}$-eGFP in $293 \mathrm{~T}$ cells. At $10 \mu \mathrm{M}$, their driven $\mathrm{M}^{\mathrm{Pro}}$-eGFP expression is lower than half of the plateau level of $\mathrm{M}^{\text {Pro }}$-eGFP observed for MPI16-19. For these four inhibitors, their $\mathrm{EC}_{50}$ values are estimated as higher than $2 \mu \mathrm{M}$ for MPI20-21 and higher than $10 \mu \mathrm{M}$ for MPI22-23. Among MPI24-28 (Figure 4D), MPI25-27 exhibit high in cellulo potency with $\mathrm{EC}_{50}$ values as 140 $\mathrm{nM}, 230 \mathrm{nM}$, and $630 \mathrm{nM}$ respectively. On contrary to their high in vitro enzyme inhibition potency, MPI24 and MPI28 have very weak in cellulo potency with estimated $\mathrm{EC}_{50}$ values as higher than $2 \mu \mathrm{M}$ and higher than $10 \mu \mathrm{M}$, respectively.
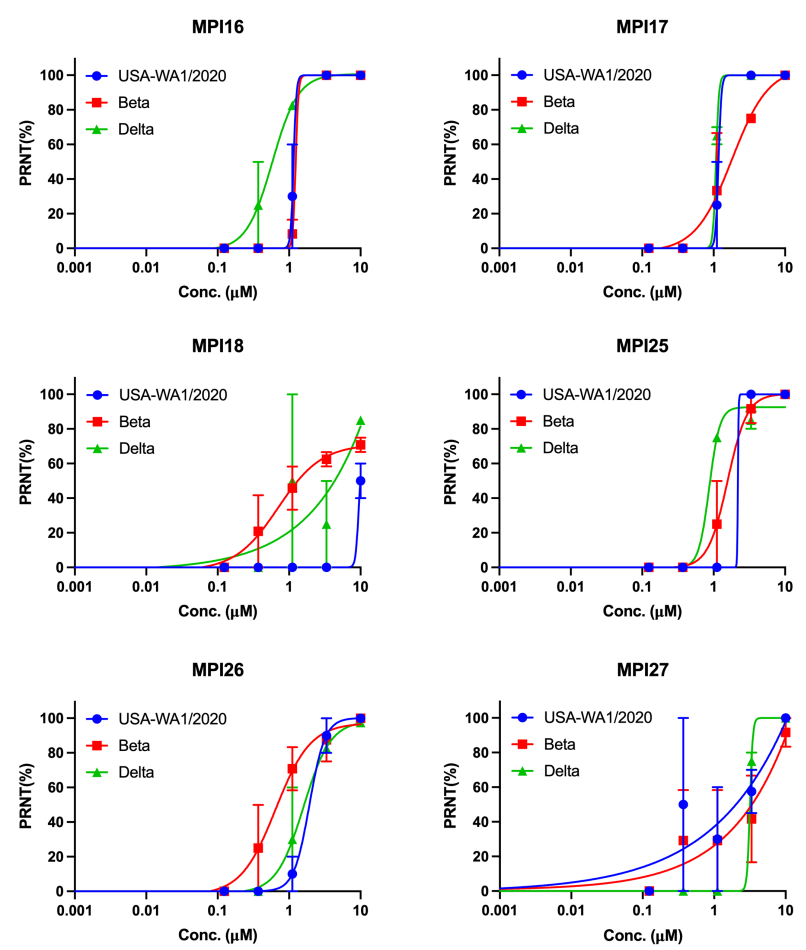

Figure 5. Plaque reduction neutralization tests (PRNTs) of MPI16-18 and MPI25-27 on their inhibition of three SARSCoV-2 strains USA-WA1/2020, Beta and Delta in Vero E6 cells. Two repeats were conducted for each concentration.

Characterizations of antiviral potency of six selected inhibitors on three SARS-CoV-2 variants. Four most cellularly potent inhibitors MPI16, MPI17, MPI25, and MPI26 that contain a P3 O-tert-butyl-threonine and two mildly cellularly potent inhibitors MPI18 and MPI27 that don't contain a P3 O-tert-butyl-threonine were analyzed on their antiviral potency against three SARS-CoV-2 variants including USA-WA1/2020, Beta and Delta. We conducted plaque reduction neutralization tests in Vero E6 cells for all inhibitors. We infected Vero E6 cells by virus in the presence of an inhibitor at various concentrations for three days and then quantified viral plaque reduction. As presented in the attached figure and table, all four inhibitors that contain a P3 O-tert-butyl-threonine showed high antiviral potency with determined $\mathrm{EC}_{50}$ values 
Table 1: Determined enzymatic $\mathrm{IC}_{50}$ and cellular $\mathrm{EC}_{50}$ values of $\mathrm{M}^{\text {Pro }}$ inhibitors

\begin{tabular}{|c|c|c|c|c|c|c|c|c|c|}
\hline ID & $\begin{array}{l}\text { Enzymatic } \\
\mathrm{IC}_{50}(\mathrm{nM})\end{array}$ & $\begin{array}{l}\text { Cellular } \\
\mathrm{EC}_{50}(\mu \mathrm{M})\end{array}$ & $\begin{array}{l}\text { Antiviral } \mathrm{EC}_{50} \\
(\mu \mathrm{M})\end{array}$ & $\begin{array}{l}\text { PDB } \\
\text { Entry }\end{array}$ & ID & $\begin{array}{l}\text { Enzymatic } \\
\mathrm{IC}_{50}(\mathrm{nM})\end{array}$ & $\begin{array}{l}\text { Cellular } \\
\mathrm{EC}_{50}(\mu \mathrm{M})\end{array}$ & $\begin{array}{l}\text { Antiviral } \mathrm{EC}_{50} \\
(\mu \mathrm{M})\end{array}$ & $\begin{array}{l}\text { PDB } \\
\text { Entry }\end{array}$ \\
\hline MPI3 & $8.5^{b}$ & $>2^{c}$ & & $7 J Q 0$ & MPI17 & 60 & 0.097 & $1.2^{\mathrm{e}} / 1.8^{\mathrm{f}} / 1.1^{\mathrm{g}}$ & - \\
\hline MPI4 & $15^{b}$ & $>2^{c}$ & & $7 J Q 1$ & MPI18 & 36 & 0.86 & $>5^{\mathrm{e}} / 0.71^{\mathrm{f}} />5^{\mathrm{g}}$ & 7RVR \\
\hline MPI5 & $33^{b}$ & $0.66^{c}$ & & 7JQ2 & MPI19 & 13 & 1.5 & & 7RVS \\
\hline MPI6 & $60^{b}$ & $0.12^{c}$ & & $7 J Q 3$ & MPI20 & 16 & $>2$ & & 7RVT \\
\hline MPI7 & $47^{b}$ & $0.19^{c}$ & & $7 J Q 4$ & MPI21 & 77 & $>2$ & & $7 \mathrm{RVU}$ \\
\hline MPI8 & $105^{b}$ & $0.03^{c}$ & & 7JQ5 & MPI22 & 49 & $>10$ & & 7RVV \\
\hline MPI11 & 8.8 & $>2$ & & 7RVM & MPI23 & 350 & $>10$ & & 7RVW \\
\hline MPI12 & 11 & $>2$ & & 7RVN & MPI24 & 8.4 & $>2$ & & 7RVX \\
\hline MPI13 & $4.8^{\mathrm{d}}$ & $>2$ & & $7 \mathrm{RVO}$ & MPI25 & 650 & 0.14 & $2.2^{\mathrm{e}} / 1.6^{\mathrm{f}} / 0.87^{\mathrm{g}}$ & $7 \mathrm{RVY}$ \\
\hline MPI14 & $5.2^{\mathrm{d}}$ & $>2$ & & 7RVP & MPI26 & 530 & 0.23 & $1.9^{\mathrm{e}} / 0.65^{\mathrm{f}} / 1.6^{\mathrm{g}}$ & $7 \mathrm{RVZ}$ \\
\hline MPI15 & n.d. & n.d. & & - & MPI27 & 160 & 0.63 & $>5^{\mathrm{e}} />5^{\mathrm{f}} / 3.2^{\mathrm{g}}$ & 7RW0 \\
\hline MPI16 & 150 & 0.056 & $1.2^{\mathrm{e}} / 1.2^{\mathrm{f}} / 0.58^{\mathrm{g}}$ & $7 \mathrm{RVQ}$ & MPI28 & 52 & $>10$ & & 7RW1 \\
\hline
\end{tabular}

${ }^{\mathrm{a}}$ Its $\mathrm{IC}_{50}$ and $\mathrm{EC}_{50}$ values were not determined (n.d.) due to insolubility.

${ }^{b}$ Data were taken from ref. ${ }^{13}$.

${ }^{\mathrm{c}}$ Data were taken from ref. ${ }^{29}$.

${ }^{\mathrm{d}}$ Reaching the detection limit.

${ }^{\mathrm{e}}$ Antiviral $\mathrm{EC}_{50}$ value for the USA-WA1/2020 strain.

${ }^{\mathrm{f}}$ Antiviral $\mathrm{EC}_{50}$ value for the Beta strain.

${ }^{\mathrm{g}}$ Antiviral $\mathrm{EC}_{50}$ value for the Delta strain.

around $1 \mu \mathrm{M}$. Except MPI8 on the Beta strain, MPI18 and MPI27 that don't have a P3 O-tert-butyl-threonine showed only mild antiviral potency. These antiviral results support that P3 O-tert-butyl-threonine in a peptidyl aldehyde inhibitor leads to high antiviral potency.

\section{- DISCUSSION}

There are 11 unique proteolytic sites in pp1a and pp1b that are hydrolyzed by $\mathrm{M}^{\text {Pro }}$. Glutamine is a strictly required residue at the $\mathrm{P} 1$ site for all 11 sites. Due to this strict requirement and medicinal chemistry information learnt from the same function enzyme in SARS-CoV, most peptidyl inhibitors that have been developed for $\mathrm{M}^{\text {Pro }}$ have maintained a $\beta$-(S-2-oxopyrrolidin-3-yl)-alanine analog at the $\mathrm{P} 1$ site for improved potency. In our design, we keep opal at this site for all inhibitors. Our crystallography results show a well-shaped opal side chain in all $\mathrm{M}^{\text {Pro }}$-inhibitor complexes that fits neatly in the P1 binding pocket of the enzyme. Since opal is optimized for this site, there is small chemical space to manipulate its side chain for improved binding. In all determined structures, the side chain of N142 adopts different conformations that do not necessarily interact with the opal oxopyrrolidine ring. It may be possible to modify the opal oxopyrrolidine ring to introduce interactions such as hydrogen bonding with the side chain of N142 for improved binding. Among all $11 \mathrm{M}^{\mathrm{Pro}}$-targeted proteolytic sites, 9 have a $\mathrm{P} 2$ leucine, 1 has a $\mathrm{P} 2$ phenylalanine, and 1 has a $\mathrm{P} 2$ valine. The enzyme has an apparent preference for a P2 leucine in its substrates. A comparison of in vitro enzyme inhibition potency for all MPIs that we have developed also reveals that $\mathrm{M}^{\text {Pro }}$ prefers a $\mathrm{P} 2$ residue with a similar size as leucine in a peptidyl inhibitor for favorable binding. Converting the isopropyl group at the $\beta$-carbon of the P2 leucine to cyclopropyl and 2-furanyl improves the enzyme inhibition kinetics. Although changing the P2 leucine in an inhibitor to a larger residue such as phenylalanine and $\beta$-cyclohexylalanine diminishes in vitro $\mathrm{M}^{\text {Pro }}$ inhibition potency, the level is not significant.

$\mathrm{M}^{\text {Pro }}$ shows almost no preference to the $\mathrm{P} 3$ residue in its targeted proteolytic sites in pp 1a and pplb. We explored a variety of chemical variants at this site including dialkyl glycines and 1-aminocyclopropane-1-carboxylate that have no $\alpha$-proton. Although $\mathrm{M}^{\mathrm{Pro}}$ displays a clear preference for a P3 valine, other substituents at this site are well tolerated. Given the diverse structures of tolerable chemical compositions at this site, D-amino acids might be introduced at this site for the development of novel $\mathrm{M}^{\text {Pro }}$ inhibitors. This will need to be explored further. All our crystal structures show weak electron density around the $N$-terminal group indicating its weak binding to the enzyme. Adding a $m$-chloride to the $N$-terminal CBZ group also leads to significant decrease in in vitro enzyme inhibition potency. Our study indicates that both CBZ and indole-2-carboxyl are not optimal chemical groups for interactions with $\mathrm{M}^{\text {Pro }}$. Some smaller groups need to be explored at this site.

Although most inhibitors we have developed in this study exhibit very high in vitro enzyme inhibition potency and two inhibitors have $\mathrm{IC}_{50}$ values reaching the characterization limit, just a few inhibitors show in cellulo potency to inhibit $\mathrm{M}^{\text {Pro }}$ in $293 \mathrm{~T}$ cells. Inhibitors that have a P3 O-tert-butyl-threonine all show high in cellulo potency. All other P3 substituents lead to low in cellulo potency. Many factors may contribute to this phenomenon. Since all MPIs are peptidyl inhibitors, a small or native P3 residue might be prone to proteolytic degradation by host proteases leading to low in cellulo potency. This is 
partially supported by characterizable in cellulo potency for MPI18-19 that have a P3 $\beta$-tert-butyl-alanine. It is also possible that a $\mathrm{P} 3 \mathrm{O}$-tert-butyl-threonine introduces more favorable cellular permeability than other P3 substituents into an $\mathrm{M}^{\text {Pro }}$ inhibitor. MPI21-23 that have a P3 dialkylglycine are expected to be more resistant to proteolytic digestion by human proteases than other MPIs. Their low in cellulo potency might be due to low cellular permeability. Based on in cellulo potency of MPIs, we can also derive that an $N$-terminal CBZ group works better than the other two groups that have been tested at this site and a P2 $\beta$-cyclohexylalanine favors high in cellulo potency.

\section{- CONCLUSIONS}

In combination with our previous studies, ${ }^{13,29}$ we can conclude that a P3 O-tert-butyl-threonine in peptidyl aldehyde inhibitors for $\mathrm{M}^{\text {Pro }}$ is optimal for high in cellulo and antiviral potency. This new and critical finding will be highly useful for the development of novel antiviral lead series and drug candidates with potential to treat COVID-19. However, chemical compositions at the P2 site and the $N$-terminal group in peptidyl aldehyde inhibitors for optimal in cellulo and antiviral potency need to be explored further.

\section{- EXPERIMENTAL SECTION}

\section{ASSOCIATED CONTENT}

Supporting Information.

The Supporting Information is available free of charge on the ACS Publications website.

Supplementary information for the synthesis of MPI11-28, NMR spectrascopies and HPLC chromatographies of MPI11-28, X-ray data collection and processing parameters, and all original flow cytometry graphs. All compounds are $>95 \%$ pure by HPLC analysis.

\section{ACKNOWLEDGMENT}

This work was supported by Welch Foundation (grant A1715), DHHS-NIH-National Institute of Allergy and Infectious Diseases (R21AI164088), TAMU COS Strategic Transformative Research Program, and Texas A\&M X Grants. The ALS-ENABLE beam-lines are supported in part by the National Institutes of Health, National Institute of General Medical Sciences, grant P30 GM124169-01 and the Howard Hughes Medical Institute. The Advanced Light Source is a Department of Energy Office of Science User Facility under Contract No. DE-AC02-05CH11231.

\section{REFERENCE}

1. Lan, J.; Ge, J.; Yu, J.; Shan, S.; Zhou, H.; Fan, S.; Zhang, Q.; Shi, X.; Wang, Q.; Zhang, L.; Wang, X., Structure of the SARS-CoV-2 spike receptor-binding domain bound to the ACE2 receptor. Nature 2020, 581 (7807), 215-220.

2. Yan, R.; Zhang, Y.; Li, Y.; Xia, L.; Guo, Y.; Zhou, Q., Structural basis for the recognition of SARS-CoV-2 by fulllength human ACE2. Science 2020, 367 (6485), 1444-1448.

3. Kim, D.; Lee, J. Y.; Yang, J. S.; Kim, J. W.; Kim, V. N.; Chang, H., The Architecture of SARS-CoV-2 Transcriptome. Cell 2020, 181 (4), 914-921 e10.

4. Zhou, P.; Yang, X. L.; Wang, X. G.; Hu, B.; Zhang, L.; Zhang, W.; Si, H. R.; Zhu, Y.; Li, B.; Huang, C. L.; Chen, H. D.; Chen, J.; Luo, Y.; Guo, H.; Jiang, R. D.; Liu, M. Q.; Chen, Y.; Shen, X. R.; Wang, X.; Zheng, X. S.; Zhao, K.; Chen, Q. J.; Deng, F.; Liu, L. L.; Yan, B.; Zhan, F. X.; Wang, Y. Y.; Xiao, G. F.; Shi,Z.L., A pneumonia outbreak associated with a new coronavirus of probable bat origin. Nature 2020, 579 (7798), 270-273

5. Morse, J. S.; Lalonde, T.; Xu, S.; Liu, W. R., Learning from the Past: Possible Urgent Prevention and Treatment Options for Severe Acute Respiratory Infections Caused by 2019nCoV. Chembiochem 2020, 21 (5), 730-738.

6. Dai, W.; Zhang, B.; Jiang, X. M.; Su, H.; Li, J.; Zhao, Y.; Xie, X.; Jin, Z.; Peng, J.; Liu, F.; Li, C.; Li, Y.; Bai, F.; Wang, H.; Cheng, X.; Cen, X.; Hu, S.; Yang, X.; Wang, J.; Liu, X.; Xiao, G.; Jiang, H.; Rao, Z.; Zhang, L. K.; Xu, Y.; Yang, H.; Liu, H., Structure-based design of antiviral drug candidates targeting the SARS-CoV-2 main protease. Science 2020, 368 (6497), 1331-1335.

7. Fu, L.; Ye, F.; Feng, Y.; Yu, F.; Wang, Q.; Wu, Y.; Zhao, C.; Sun, H.; Huang, B.; Niu, P.; Song, H.; Shi, Y.; Li, X.; Tan, W.; Qi, J.; Gao, G. F., Both Boceprevir and GC376 efficaciously inhibit SARS-CoV-2 by targeting its main protease. Nat Commun 2020, 11 (1), 4417.

8. Dai, W.; Jochmans, D.; Xie, H.; Yang, H.; Li, J.; Su, H.; Chang, D.; Wang, J.; Peng, J.; Zhu, L.; Nian, Y.; Hilgenfeld, R.; Jiang, H.; Chen, K.; Zhang, L.; Xu, Y.; Neyts, J.; Liu, H., Design, Synthesis, and Biological Evaluation of Peptidomimetic Aldehydes as Broad-Spectrum Inhibitors against Enterovirus and SARS-CoV-2. J Med Chem 2021, 10.1021/acs.jmedchem.0c02258.

9. Qiao, J.; Li, Y. S.; Zeng, R.; Liu, F. L.; Luo, R. H.; Huang, C.; Wang, Y. F.; Zhang, J.; Quan, B.; Shen, C.; Mao, X.; Liu, X.; Sun, W.; Yang, W.; Ni, X.; Wang, K.; Xu, L.; Duan, Z. L.; Zou, Q. C.; Zhang, H. L.; Qu, W.; Long, Y. H.; Li, M. H.; Yang, R. C.; Liu, X.; You, J.; Zhou, Y.; Yao, R.; Li, W. P.; Liu, J. M.; Chen, P.; Liu, Y.; Lin, G. F.; Yang, X.; Zou, J.; Li, L.; Hu, Y.; Lu, G. W.; Li, W. M.; Wei, Y. Q.; Zheng, Y. T.; Lei, J.; Yang, S., SARS-CoV-2 M(pro) inhibitors with antiviral activity in a transgenic mouse model. Science 2021, 371 (6536), 1374-1378.

10. Hoffman, R. L.; Kania, R. S.; Brothers, M. A.; Davies, J. F.; Ferre, R. A.; Gajiwala, K. S.; He, M.; Hogan, R. J.; Kozminski, K.; Li, L. Y.; Lockner, J. W.; Lou, J.; Marra, M. T.; Mitchell, L. J., Jr.; Murray, B. W.; Nieman, J. A.; Noell, S.; Planken, S. P.; Rowe, T.; Ryan, K.; Smith, G. J., 3rd; Solowiej, J. E.; Steppan, C. M.; Taggart, B., Discovery of Ketone-Based Covalent Inhibitors of Coronavirus 3CL Proteases for the Potential Therapeutic Treatment of COVID19. J Med Chem 2020, 63 (21), 12725-12747.

11. Ma, C.; Sacco, M. D.; Hurst, B.; Townsend, J. A.; Hu, Y.; Szeto, T.; Zhang, X.; Tarbet, B.; Marty, M. T.; Chen, Y.; Wang, J., Boceprevir, GC-376, and calpain inhibitors II, XII inhibit SARS-CoV-2 viral replication by targeting the viral main protease. Cell Res 2020,30 (8), 678-692. 
12. Sacco, M. D.; Ma, C.; Lagarias, P.; Gao, A.; Townsend, J. A.; Meng, X.; Dube, P.; Zhang, X.; Hu, Y.; Kitamura, N.; Hurst, B.; Tarbet, B.; Marty, M. T.; Kolocouris, A.; Xiang, Y.; Chen, Y.; Wang, J., Structure and inhibition of the SARS-CoV-2 main protease reveal strategy for developing dual inhibitors against $\mathrm{M}$ (pro) and cathepsin L. Sci Adv 2020, 6 (50), eabe 0750 .

13. Yang, K. S.; Ma, X. R.; Ma, Y.; Alugubelli, Y. R.; Scott, D. A.; Vatansever, E. C.; Drelich, A. K.; Sankaran, B.; Geng, Z. Z.; Blankenship, L. R.; Ward, H. E.; Sheng, Y. J.; Hsu, J. C.; Kratch, K. C.; Zhao, B.; Hayatshahi, H. S.; Liu, J.; Li, P.; Fierke, C. A.; Tseng, C. K.; Xu, S.; Liu, W. R., A Quick Route to Multiple Highly Potent SARS-CoV-2 Main Protease Inhibitors*. ChemMedChem 2021, 16 (6), 942-948.

14. Ma,X. R.; Alugubelli, Y. R.; Ma, Y.; Vatansever, E. C.; Scott, D. A.; Qiao, Y.; Yu, G.; Xu, S.; Liu, W. R., MPI8 is Potent against SARS-CoV-2 by Inhibiting Dually and Selectively the SARS-CoV-2 Main Protease and the Host Cathepsin L*. ChemMedChem 2021, 10.1002/cmdc.202100456.

15. Douangamath, A.; Fearon, D.; Gehrtz, P.; Krojer, T.; Lukacik, P.; Owen, C. D.; Resnick, E.; Strain-Damerell, C.; Aimon, A.; Abranyi-Balogh, P.; Brandao-Neto, J.; Carbery, A.; Davison, G.; Dias, A.; Downes, T. D.; Dunnett, L.; Fairhead, M.; Firth, J. D.; Jones, S. P.; Keeley, A.; Keseru, G. M.; Klein, H. F.; Martin, M. P.; Noble, M. E. M.; O'Brien, P.; Powell, A.; Reddi, R. N.; Skyner, R.; Snee, M.; Waring, M. J.; Wild, C.; London, N.; von Delft, F.; Walsh, M. A., Crystallographic and electrophilic fragment screening of the SARS-CoV-2 main protease. Nat Commun 2020, 11 (1), 5047.

16. Ghahremanpour, M. M.; Tirado-Rives, J.; Deshmukh, M.; Ippolito, J. A.; Zhang, C. H.; Cabeza de Vaca, I.; Liosi, M. E.; Anderson, K. S.; Jorgensen, W. L., Identification of 14 Known Drugs as Inhibitors of the Main Protease of SARS-CoV-2. ACS Med Chem Lett 2020, 11 (12), 2526-2533.

17. Jin, Z.; Du, X.; Xu, Y.; Deng, Y.; Liu, M.; Zhao, Y.; Zhang, B.; Li, X.; Zhang, L.; Peng, C.; Duan, Y.; Yu, J.; Wang, L.; Yang, K.; Liu, F.; Jiang, R.; Yang, X.; You, T.; Liu, X.; Yang, X.; Bai, F.; Liu, H.; Liu, X.; Guddat, L. W.; Xu, W.; Xiao, G.; Qin, C.; Shi, Z.; Jiang, H.; Rao, Z.; Yang, H., Structure of $\mathrm{M}$ (pro) from SARS-CoV-2 and discovery of its inhibitors. Nature 2020, 582 (7811), 289-293.

18. Jin, Z.; Zhao, Y.; Sun, Y.; Zhang, B.; Wang, H.; Wu, Y.; Zhu, Y.; Zhu, C.; Hu, T.; Du, X.; Duan, Y.; Yu, J.; Yang, X.; Yang, X.; Yang, K.; Liu, X.; Guddat, L. W.; Xiao, G.; Zhang, L.; Yang, H.; Rao, Z., Structural basis for the inhibition of SARSCoV-2 main protease by antineoplastic drug carmofur. Nat Struct Mol Biol 2020, 27 (6), 529-532.

19. Мa, C.; Hu, Y.; Townsend, J. A.; Lagarias, P. I.; Marty, M. T.; Kolocouris, A.; Wang, J., Ebselen, Disulfiram, Carmofur, PX-12, Tideglusib, and Shikonin Are Nonspecific Promiscuous SARS-CoV-2 Main Protease Inhibitors. ACS Pharmacol Transl Sci 2020, 3 (6), 1265-1277.

20. Rathnayake, A. D.; Zheng, J.; Kim, Y.; Perera, K. D.; Mackin, S.; Meyerholz, D. K.; Kashipathy, M. M.; Battaile, K. P.; Lovell, S.; Perlman, S.; Groutas, W. C.; Chang, K. O., 3C-like protease inhibitors block coronavirus replication in vitro and improve survival in MERS-CoV-infected mice. Sci Transl Med 2020, 12(557), eabc5332.

21. Zhu, W.; Xu, M.; Chen, C. Z.; Guo, H.; Shen, M.; Hu, X.; Shinn, P.; Klumpp-Thomas, C.; Michael, S. G.; Zheng, W., Identification of SARS-CoV-2 3CL Protease Inhibitors by a Quantitative High-Throughput Screening. ACS Pharmacol Transl Sci 2020, 3 (5), 1008-1016.

22. Gunther, S.; Reinke, P. Y. A.; Fernandez-Garcia, Y.; Lieske, J.; Lane, T. J.; Ginn, H. M.; Koua, F. H. M.; Ehrt, C.; Ewert, W.; Oberthuer, D.; Yefanov, O.; Meier, S.; Lorenzen, K.;
Krichel, B.; Kopicki, J. D.; Gelisio, L.; Brehm, W.; Dunkel, I.; Seychell, B.; Gieseler, H.; Norton-Baker, B.; EscuderoPerez, B.; Domaracky, M.; Saouane, S.; Tolstikova, A.; White, T. A.; Hanle, A.; Groessler, M.; Fleckenstein, H.; Trost, F.; Galchenkova, M.; Gevorkov, Y.; Li, C.; Awel, S.; Peck, A.; Barthelmess, M.; Schlunzen, F.; Lourdu Xavier, P.; Werner, N.; Andaleeb, H.; Ullah, N.; Falke, S.; Srinivasan, V.; Franca, B. A.; Schwinzer, M.; Brognaro, H.; Rogers, C.; Melo, D.; Zaitseva-Doyle, J. J.; Knoska, J.; Pena-Murillo, G. E.; Mashhour, A. R.; Hennicke, V.; Fischer, P.; Hakanpaa, J.; Meyer, J.; Gribbon, P.; Ellinger, B.; Kuzikov, M.; Wolf, M.; Beccari, A. R.; Bourenkov, G.; von Stetten, D.; Pompidor, G.; Bento, I.; Panneerselvam, S.; Karpics, I.; Schneider, T. R.; Garcia-Alai, M. M.; Niebling, S.; Gunther, C.; Schmidt, C.; Schubert, R.; Han, H.; Boger, J.; Monteiro, D. C. F.; Zhang, L.; Sun, X.; Pletzer-Zelgert, J.; Wollenhaupt, J.; Feiler, C. G.; Weiss, M. S.; Schulz, E.C.; Mehrabi,P.; Karnicar, K.; Usenik, A.; Loboda, J.; Tidow, H.; Chari, A.; Hilgenfeld, R.; Uetrecht, C.; Cox, R.; Zaliani, A.; Beck, T.; Rarey, M.; Gunther, S.; Turk, D.; Hinrichs, W.; Chapman, H. N.; Pearson, A. R.; Betzel, C.; Meents, A., X-ray screening identifies active site and allosteric inhibitors of SARS-CoV-2 main protease. Science 2021, 372 (6542), 642-646.

23. Hattori, S. I.; Higashi-Kuwata, N.; Hayashi, H.; Allu, S. R.; Raghavaiah, J.; Bulut, H.; Das, D.; Anson, B. J.; Lendy, E. K.; Takamatsu, Y.; Takamune, N.; Kishimoto, N.; Murayama, K.; Hasegawa, K.; Li, M.; Davis, D. A.; Kodama, E. N.; Yarchoan, R.; Wlodawer, A.; Misumi, S.; Mesecar, A. D.; Ghosh, A. K.; Mitsuya, H., A small molecule compound with an indole moiety inhibits the main protease of SARS-CoV-2 and blocks virus replication. Nat Commun 2021, 12 (1), 668.

24. Kuo, C. J.; Chao, T. L.; Kao, H. C.; Tsai, Y. M.; Liu, Y. K.; Wang, L. H.; Hsieh, M. C.; Chang, S. Y.; Liang, P. H., Kinetic characterization and inhibitor screening for the proteases leading to identification of drugs against SARS-CoV-2. Antimicrob Agents Chemother 2021, 65(4), e02577-20.

25. Lockbaum, G. J.; Reyes, A. C.; Lee, J. M.; Tilvawala, R.; Nalivaika, E. A.; Ali, A.; Kurt Yilmaz, N.; Thompson, P. R.; Schiffer, C. A., Crystal Structure of SARS-CoV-2 Main Protease in Complex with the Non-Covalent Inhibitor ML188. Viruses 2021, 13 (2), 174.

26. Zaidman, D.; Gehrtz, P.; Filep, M.; Fearon, D.; Gabizon, R.; Douangamath, A.; Prilusky, J.; Duberstein, S.; Cohen, G.; Owen, C. D.; Resnick, E.; Strain-Damerell, C.; Lukacik, P.; Covid-Moonshot, C.; Barr, H.; Walsh, M. A.; von Delft, F.; London, N., An automatic pipeline for the design of irreversible derivatives identifies a potent SARS-CoV-2 M(pro) inhibitor. Cell Chem Biol 2021, 10.1016/j.chembiol.2021.05018.

27. Zhang, C. H.; Stone, E. A.; Deshmukh, M.; Ippolito, J. A.; Ghahremanpour, M. M.; Tirado-Rives, J.; Spasov, K. A.; Zhang, S.; Takeo, Y.; Kudalkar, S. N.; Liang, Z.; Isaacs, F.; Lindenbach, B.; Miller, S. J.; Anderson, K. S.; Jorgensen, W. L., Potent Noncovalent Inhibitors of the Main Protease of SARS-CoV-2 from Molecular Sculpting of the Drug Perampanel Guided by Free Energy Perturbation Calculations. ACS Cent Sci 2021, 7 (3), 467-475.

28. Vatansever, E. C.; Yang, K. S.; Drelich, A. K.; Kratch, K. C.; Cho, C. C.; Kempaiah, K. R.; Hsu, J. C.; Mellott, D. M.; Xu, S.; Tseng, C. K.; Liu, W. R., Bepridil is potent against SARSCoV-2 in vitro. Proc Natl Acad Sci U S A 2021, 118 (10), e2012201118.

29. Cao, W.; Cho, C.-C. D.; Geng, Z. Z.; Ma, X. R.; Allen, R.; Shaabani, N.; Vatansever, E. C.; Alugubelli, Y. R.; Ma, Y.; Ellenburg, W. H.; Yang, K. S.; Qiao, Y.; Ji, H.; Xu, S.; Liu, W. R., Cellular Activities of SARS-CoV-2 Main Protease 
bioRxiv preprint doi: https://doi.org/10.1101/2021.12.18.473326; this version posted December 21, 2021. The copyright holder for this preprint (which was not certified by peer review) is the author/funder. All rights reserved. No reuse allowed without permission.

Inhibitors Reveal Their Unique Characteristics. bioRxiv 2021, 2021.06.08.447613. 
O-tert-butyl-threonine at P3 site is a key component to achieve high cellular and antiviral potency

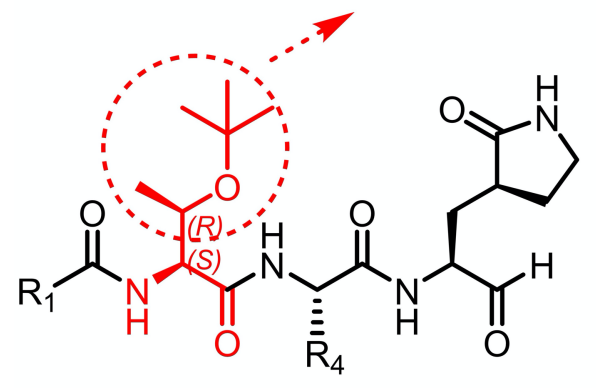

SARS-CoV-2 $\mathrm{M}^{\text {Pro }}$ inhibitors 